insertarse en la vida americana de la que se sienten marginados, $u$ otros grupos generacionales.

Por otro lado, como reconoce Gibert, los españoles no somos especialmente partidarios de cultivar el género autobiográfico, quizá por exceso de individualismo, al contrario de lo que ocurre en Norteamérica, donde su importancia es tan clara que se reconoce oficialmente como una forma característica de la expresión americana, desde las memorias «trascendentales» 0 «proféticas» de los puritanos, con su simpatía por la tipología, hasta la novela autobiográfica de Frank Conroy o Alfred Kazin, donde el autor, el narrador y el protagonista se separan y diversifican, y sólo conoce el lector que se trata de una obra autobiográfica por la intención con que se acerca a ella.

En la autobiografía de Rafael Gibert no se nos plantean estos problemas de interpretación. Advertimos, en primer lugar, un sentimiento de afiliación al pasado, a las personas que poblaron su mundo, no sólo las dos figuras de sus padres, que son las que aparecen más destacadas en todo el entorno familiar, sino también esos personajes imborrables, esas deliciosas figuras que pueblan su mundo infantil y que ve ahora en torno a su mesa, pidiéndole que no las olvide: el «calvo y pintarrajeado Lliyi, casi centenario, con sus lamentaciones jeremíacas», el célebre «Pintor, que cambió los pinceles por el gancho de marisquero», o el venerado «médico de los perros con los pies en la tierra y la cabeza en el laberinto interplanetario» (pág. 71). En segundo lugar, el significado que esas memorias tienen para él, a veces llenas de profunda tristeza: «El huérfano, ovillado, va por su atajo diendo: "igracias, gracias!" A los padres nunca dijo "gracias", ni cuando lo arropaban. Ahora, el enfado es pecado, y la risa es pecado» (pág. 90). Y, por último, como entorno y marco de todo ese conglomerado de personajes y significados, aparece la ciudad de Ceuta, su tierra, la ciudad blanca y azul entre cuyas murallas convivian tres religiones en hermosa tolerancia fraternal: «Nada nos es ajeno en el ambiente de la ciudad en que se nace» (pág. 112),

... su recuerdo vive en $\mathrm{mi}$ -después de 35 años de ausencia- saturado de un nostálgico deseo de retorno (pág. 21).

\section{Antonia Álvarez Calleja}

LOPE DE VEGA: Rimas I [Doscientos sonetos]. Edición crítica y anotada de Felipe B. Pedraza Jiménez. Universidad de Castilla-La Mancha, 1993. 676 págs.

La Universidad de Castilla-La Mancha nos ofrece el primer volumen 
de las Rimas de Lope de edición crítica y anotada. El volumen viene a llenar un gran vacío existente en la bibliografía de Lope, al proporcionarnos un texto científicamente fiable, fruto de una labor de investigación y minuciosa colación de los principales manuscritos y ediciones del Fénix; y se une a una serie de ediciones de poesía de nuestro Siglo de Oro, entre las cuales cabe mencionar la de Quevedo, realizada por José Manuel Blecua en la editorial Castalia, y la edición de Biruté Ciplijauskaité de los Sonetos de Góngora en la Universidad de Madison, a cuyo proyecto se halla más cercano éste de Felipe B. Pedraza. El profesor Pedraza lleva varios años dedicado al estudio y edición de la lírica lopista: aparte del Lope de Vega (Barcelona, Teide, 1990), ya en 1984 y 1985 dio a la luz, en la editorial Ara Iovis, sendos facsímiles de las ediciones príncipies de las Rimas. Los doscientos sonetos (Madrid, 1602) y de la Segunda parte de las Rimas (Sevilla, 1604) y en 1990, en la editorial Taurus, una antología con el título de Lope de Vega esencial; esta labor desembocó en su tesis doctoral, Edición y estudio de las «Rimas» de Lope de Vega (Barcelona, 1991), condensada en la edición que nos ocupa.

En dos grandes apartados podemos dividir el presente trabajo de $\mathrm{Pe}$ draza: fijar y depurar el texto de los sonetos; $y$ hacerlo comprensible al lector, especialmente al estudiante universitario. Para lo primero, tras la colación de las ediciones, totales y parciales, manuscritos y antologías en los que podemos encontrar alguna de las composiciones, crea un stemma en el que, aparte un discutible arquetipo (¿se puede hablar de arquetipo, cuando el autor supervisa las diferentes ediciones; cuando no se trata de errores de copistas o tipógrafos, sino de diferentes redacciones, cada una de ellas avaladas por el propio poeta?), muestra cómo se fue formando la obra desde la primitiva publicación de los doscientos sonetos a continuación de La hermosura de Angélica (Madrid, 1602); la edición independiente de las Rimas (Sevilla, 1604) con los textos corregios por el mismo Lope; hasta la edición del «Nuevo Arte de hacer comedias deste tiempo» al final del volumen (Madrid, 1609), con lo cual se completa la colección. De las tres proceden todas las restantes ediciones nos dice Pedraza, quien, al mismo tiempo, localiza las bibliotecas en las que se custodia alguno de los ejemplares de aquéllas.

Pero, como hemos dicho, también se interna Pedraza en el terreno de la transmión manuscrita, aunque de menos valor frente a las ediciones preparadas por el propio autor. En efecto, ha manejado hasta un total de veintitrés manuscritos poéticos y tres teatrales; además veinticuatro ediciones de comedias y diez obras antológicas o de teoría, en todas las cuales se incluye algún poema de las Rimas.

La edición crítica en sí, siguiendo las pautas de Blecua para la Obra 
poética de Francisco de Quevedo, consta de unos preliminares a cada poema en los cuales nos da cuenta de su localización en las cinco impresiones antiguas de la colección íntegra y en el resto de los manuscritos, obras teatrales y antologías, señalando en cada caso los errores evidentes y discutiéndolos, cuando resultan menos claros; sigue el texto poético, ofrecido en página impar, con una ortografía relativamente modernizada y, finalmente, en notas a pie de página, presenta las variantes y grafías originales. Con todo ello no sólo tenemos un texto digno y fiable de cada poema, sino que nos posibilita una visión global de los problemas que plantea cada composición.

Al segundo apartado (hacer comprensible el texto al lector) dedica las notas que acompañan a los textos y más de ochenta páginas de la introducción con un estudio de la relación vida-literatura en Lope de Vega. Este, que por sus complejos (era plebeyo y quería un trato de igual a igual con los nobles; era pobre, sin oficio alguno, y quería vivir como los ricos) dirige continuamente operaciones de imagen a su favor y contra quienes pudieran oscurecer su fama literaria mermándole sus ingresos (ya fuese en el campo del romancero, ya en el del teatro), desea a los cuarenta años publicar un cancionero culto. Quizás por no atreverse a darlo a la luz pública como independiente (nuestros poetas, salvo raras excepciones como ésta, huían de hacerlo), añadirá al final de
La hermosura de Angélica exclusivamente la primera parte $\mathrm{y}$, sólo dos años después (1604), las publicará enteras, formando un volumen autónomo, para el cual parecía tener licencias desde el principio; y en 1609 incorpora, como he indicado, el "Arte Nuevo».

Algunos de los poemas estaban escritos con anterioridad. Lope, no obstante, los retoca antes de incluirlos, otorgándole así al conjunto una unidad, reflejo de sus preocupaciones del momento. En las Rimas canta sus amores juveniles por Elena Osorio junto con los de Micaela Luján, «el embriagador presente de la madurez». Los sonetos - nos dice también Pedraza- se configuran de acuerdo con el modelo estructurador del Canzoniere de Petrarca, en cuanto relato de un proceso amoroso, visto serenamente (en el caso de Lope sin ojos de arrepentimiento) y con referencias a otros acontecimientos ajenos a la historia erótica que se narra, para terminar en una invocación a lo divino. Por eso, aparte de los que se refieren dicho proceso, encontramos sonetos morales, fúnebres y dedicatorios; pero en ellos la vena poética queda ahogada por lo puramente estético: el ingenio y el virtuosismo del verso.

Ahora bien, aunque resulte evidente que, en el poeta madrileño, los amores literarios coincidían con sus vivencias personales, pues llevaba a la vida su ideal literario y cantaba su propia experiencia, y que sea también manifiesto que utilizaba a menudo 
(¿qué poeta de nuestro Siglo de Oro no los empleó de alguna forma? tópicos y firmas usadas por los petrarquistas; cabe preguntarse, sin embargo, si este relato amoroso no es común al de cualquier enamorado que trate de manifestar sus sentimientos, en otras palabras, si de la obra de cualquier poeta que cante los distintos momentos de su enamoramiento no podríamos obtener un «cancionero petrarquista». En el caso de Lope echamos de menos la actitud de modelo negativo y la ausencia, además, de los poemas in morte -cosa que no ocurre en el campo del Romancero Nuevo, cuando canta sus amores con Isabel de Urbina, fallecida en 1594 (Juana de Guardo y Micaela Luján vivían en 1602) - y, lo que me parece más importante, podemos afirmar que, tal y como estudió Gregorio Marañón en su ensayo Amiel, en Lope encontramos una falta de definición de su sentimiento erótico, que me parece diametralmente opuesto al petrarquismo. En efecto, el «monstruo de la naturaleza» en distintas ocasiones, como muy bien señala Pedraza, se sirve de un mismo soneto para cantar a diferentes mujeres, es decir, su sentimiento erótico hacia lo femenino en general, se llena de un contenido determinado, según la mujer concreta que tiene delante; todo lo contrario de Petrarca con Laura. Como, por otra parte, está claro que procuraba al mismo tiempo literaturizar su vida, nos muestra siempre una actitud estudiada que como tal tenemos que entenderla.
En el cancionero el editor estudia los siguientes asuntos: el concepto de amor, su definición y sus consecuencias; los celos y la ausencia; el amor ideal, cortés y neoplatónico, y la vivencia sexual; y la mujer, tan paradójica como el mismo amor. Además analiza, breve pero profundamente, algún soneto característico de cada uno de los asuntos, discutiendo interpretaciones anteriores. De todo el examen podríamos concluir que «ni amante cortés ni platónico, aunque a veces lo creyera, el Lope de las Rimas canta amores de verdad, con su cuerpo y su alma interrelacionados».

Los doscientos sonetos son la manifestación del deseo de Lope de literaturizar cuanto le ocurre en la vida cotidiana: desde unos amores no platónicos (como los de Petrarca o Garcilaso) sino físicos con las dos cómicas, hasta, siguiendo a Tasso, los hechos más triviales que observa en el quehacer diario de alguna dama: hilar, limpiarse los dientes, consultar algún astrólogo o tener alguna enfermedad de los ojos.

La «historia» erótica empieza con el asedio a que, enamorado repentinamente por el flechazo de unos ojos azules, el poeta somete a Lucinda y los desdenes de ésta (no olvidemos que él estaba casado con Juana de Guardo y ella con Diego Díaz), los cuales son causa de llanto y lágrimas en el amante, como los que describe en romances en el caso de Belisa y Belardo; en el sitio intenta atraérsela mediante los tópicos del carpe diem o de la donna an- 
gelicata. Una segunda etapa estaría formada por los poemas que constituyen el que Pedraza denomina «ciclo de la posesión», en el cual «la vida cotidiana de Lope y Micaela se convierte en materia poética»; así los sentimientos de impaciencia y la ausencia, sublimados literariamente, se constituyen en asunto de diversos sonetos. Termina con el «ciclo de la ruptura», referido aquí a la quiebra de sus relaciones con Elena Osorio; en él destacan los famosos sonetos de los mansos.

También observa Pedraza cómo Lope, fiel hijo de su tiempo, para literaturizar sus vivencias personales se suele servir de sus conocimientos de la cultura clásica, de la historia e, incluso, de la plástica, «dentro de este concepto hay que incluir no sólo las leyendas y personajes de la mitología grecorromana, sino también los bíblicos (de Abel a Judit) y aquellos que, aun perteneciendo a la historia documentada, se han elevado a la categoría de emblema o símbolo». Pero no sólo los hallamos en los poemas que expresan sus sentimientos, sino en los morales y de circunstancias. A veces, en una estructura que Orozco llamaría manierista, expone el desarrollo del tema y, sólo al final, lo aplica a su situación; otras veces, sobre todo cuando parece describir un cuadro pictórico concreto, «la técnica es decididamente impresionista, avant la lettre», pues su narración consiste en un cúmulo de imágenes sueltas sin aparente concatenación.

Esta parte de la introducción, dedicada a hacer comprensible el texto al lector, enlaza con las notas que, en página par, acompañan a cada soneto. En ellas Pedraza ofrece: la datación del poema, cuando es posible; la relación del soneto con algún suceso de la biografía del poeta; las fuentes de algunos pasajes concretos; diversos lugares paralelos, sobre todo del propio Lope; la explicación de términos y giros sintácticos difíciles de entender, así como de las alusiones mitológicas e históricas; la relación de los críticos que han escrito sobre el soneto que se estudia, $y$ un resumen de las doctrinas de cada uno.

Como podemos observar, la labor del profesor Pedraza ha sido exhaustiva tanto en el doble aspecto de la edición crítica, depuración y fijación del texto, como en el de la edición anotada, su comprensión. Por eso no dudamos que ha de resultar de gran utilidad para cualquier lector, ya sea estudiante de literatura o investigador, ya simple aficionado a la obra del Fénix.

JosÉ RICO VERDÚ

LÓPEZ GRIGERA, Luisa: La retórica en la España del Siglo de Oro. Universidad de Salamanca, 1994, 191 págs.

Desde hace años veníamos siguiendo los escritos de la prof." Luisa López Grigera, que nos iban mostran- 